\title{
ANALYSIS AND DATA ACQUISITION METHODOLOGY BASED ON FLYING DRONES FOR THE IMPLEMENTATION OF THE INTERNET OF EVERYTHING TO SMART ARCHAEOLOGICAL AREAS
}

\author{
FABIO GARZIA ${ }^{1,2,3}$, MARA LOMBARDI $^{1}$, LUCA PAPI $^{4}$ \\ ${ }^{1}$ Safety \& Security Engineering Group - DICMA, SAPIENZA - University of Rome, Italy \\ ${ }^{2}$ Wessex Institute of Technology, Southampton, UK \\ ${ }^{3}$ European Academy of Sciences and Arts, Salzburg, Austria \\ ${ }^{4}$ Department of Engineering, ICT and Technology for Energy and Transport, CNR - Italian National Research \\ Council, Italy
}

\begin{abstract}
Cultural heritage sites such as places of archaeological interest generally extend over wide areas. Those who manage such sites need to ensure cultural heritage preservation, visitor safety, security and access and need to take into consideration visitors with disabilities.

This fundamental goal is attainable by means of integrated systems and innovative technologies, such as the Internet of Everything ( $\mathrm{IoE}$ ), which can link together people, things (mobile terminals, smart sensors, devices and actuators, wearable devices), information (data, knowledge) and processes.

Since much information is needed to design a suitable IoE-based system, necessary to realize a Smart Archaeological Area, an appropriate methodology has been developed.

The purpose of this article is to report on a suitable analysis and data acquisition method based on flying drones, necessary for the design and realization of such an IoE-based integrated system for archaeological areas. To ensure practicality, reasonable final costs, minimal risk levels and an elevated level of reliability and resilience, we consider the restrictions imposed by a typical archaeological area and use it to assess the system we have developed.

Keywords: data acquisition, data analysis, flying drones, genetic algorithms, Internet of Everything, Internet of Things, IoE integrated system, smart archaeological areas
\end{abstract}

\section{INTRODUCTION}

Cultural heritage sites such as archaeological areas extend generally over wide areas. For those sites where there is public access, there is a need for ensuring visitor safety and security, cultural heritage preservation and protection and visitor access, taking into consideration visitors with disabilities.

This fundamental goal is attainable by using integrated systems [1-5] and innovative technologies, such as the Internet of Everything (IoE), which can link together people, things (mobile terminals, smart sensors, devices and actuators, wearable devices, etc.), information (data, knowledge) and processes [6, 7].

Since a considerable amount of information is needed to design a suitable IoE-based system, necessary to realize a Smart Archaeological Area (IoE-SAA), an appropriate methodology has been developed.

Because of the typical features and restrictions of archaeological areas, represented by wide areas, a reduced possibility of installing poles and digging trenches for ground cables, ducts and so on, it is important to design a flexible and modular IoE integrated system capable of guaranteeing the desired performance at minimal cost.

Archaeological areas need different field elements, such as CCTV cameras and Wi-Fi access points (APs), to guarantee a suitable visual coverage of the areas for safety, security and protection services and a suitable coverage of wireless networks to provide IoE services. 
Because of the typical wide extension of archaeological areas, it is not only necessary to design an optimized IoE system but an optimized field element distribution is also required so as to decrease the final costs as much as possible.

For this application, we found it necessary to develop an analysis and data acquisition methodology based on flying drones (ADAM-FD), the reporting of which is the purpose of this article.

The ancient Roman 'Ocriculum' (founded in about 168 A.D.) located in Otricoli, a town in the Umbria region, in Central Italy, was chosen as the archaeological site for assessing the proposed methodology.

A detailed historical, geological and geomorphological analysis of the site was initially performed to derive fundamental information, while other, more specific data were obtained by means of flying drones. These devices provided ortho-photos, which were used to generate a digital elevation model of the terrain, as well as multi-spectral analysis, thermal analysis, vegetation index maps and three-dimensional (3D) models of the ruins. A preliminary analysis was essential to obtain information about the existing cable ducts (lighting cable ducts, for example). It was therefore possible to use these ducts for a wired optical fibre network, thus avoiding further unnecessary digging. The analysis was also necessary to localize the existing lighting poles and to locate where the installation of new poles would be permitted for the installation of field elements such as CCTV cameras and Wi-Fi APs.

A fully integrated safety and security risk analysis [8-11] was then conducted to identify the threats, and the related risks, inherent in the design of IoE-SAA. The safety and security risk analysis produced information regarding the locations for installing the necessary field elements, such as Wi-Fi APs and CCTV cameras.

The purpose of the article is to illustrate a proper ADAM-FD necessary for the design and the realization of an IoE-based integrated system properly designed for archaeological areas, using a multidisciplinary approach, which is able to ensure visitors safety and security, cultural heritage preservation/protection and great usability for visitors, with particular reference to visitors with disabilities, to guarantee a reduction of final costs, a reduction of the final risk level and a high level of reliability and resilience of the system itself, in view of the typical vincula and restrictions of archaeological areas.

\section{THE CONSIDERED ARCHAEOLOGICAL AREA}

The ancient Roman 'Ocriculum' is one of the most important archaeological sites in Umbria. It was founded in pre-Roman times on a hill on which is now located the town of Otricoli. Ocriculum was transferred, probably at the end of the Republican Era, to the plain below, in a large bend of the Tiber River, where it was developed as a port [12, 13].

Trade relations with Ancient Rome were excellent, thanks to its river port on the Tiber River, called 'Oil Port' (after olive oil) and its closeness to the Flaminia Way.

Regarding the original Roman city, the main monuments that are still visible today are represented by the amphitheatre, the thermal baths of the 2nd Century A.D., recognizable from the octagonal hall from which comes the polychrome mosaic, now in the Rotunda of the Vatican, the theatre, some larger and smaller substructures, the forum area and other public buildings such as the basilica (Fig. 1).

The site, not enclosed by walls, is crossed by the route of the ancient Flaminia Way, which is flanked by funerary monuments, before it enters the urban area.

The route along the river road greatly contributed to the development of trade and the economy, thus making it an important centre with strategic functions between Umbria and 


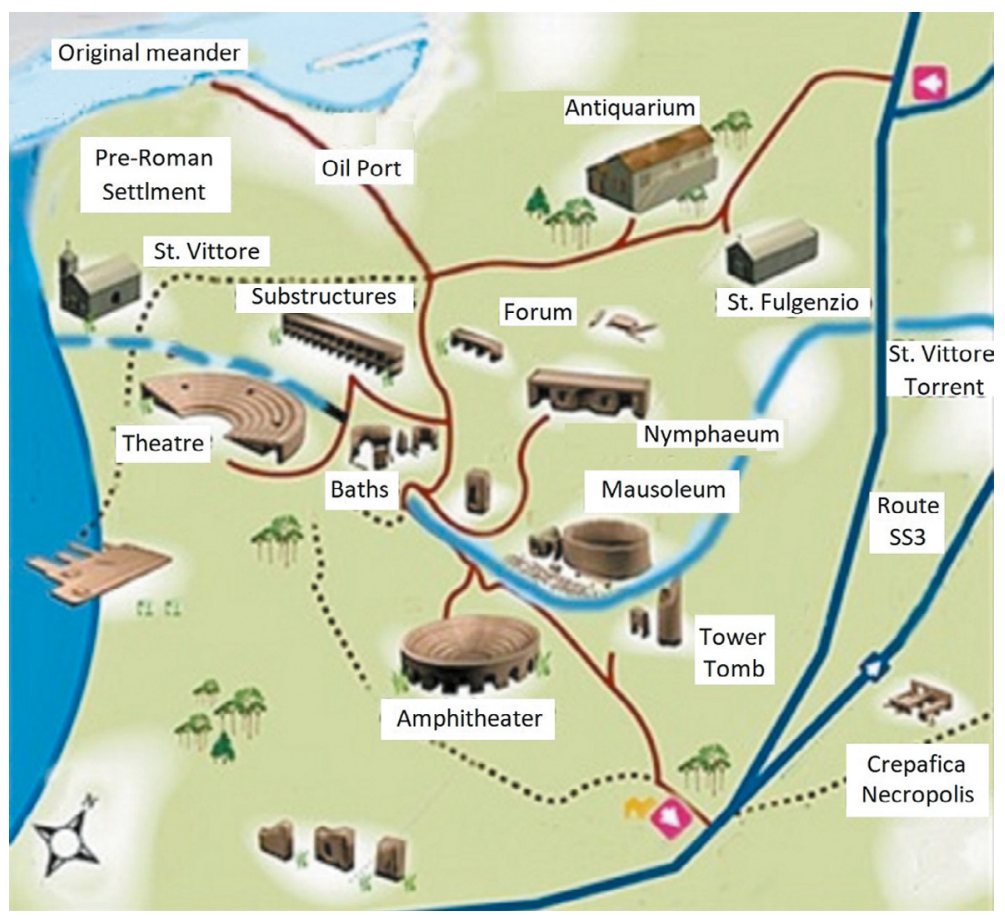

Figure 1: Map of Ocriculum archaeological site where the main monuments are shown.

Sabina (another important region of the Ancient Roman Empire). The Flaminia Way gets into Umbria region just in Ocriculum, 44 miles $(70 \mathrm{~km})$ from Rome, after crossing the Tiber River.

The amphitheatre is only partly complete and leans against the hill, which was dug out to allow support for the wall structures. The entire exterior of the monument has disappeared, but the auditorium remains, as do some parts of the intermediate gallery, topped by small rooms with sloping tiles. The two main entrances are also visible, together with the ancient arena floor and part of the podium.

The first of the monuments that it is possible to see, near the ancient Ocriculum, is represented by a niche tomb of the Imperial Age, emerging from the ground, up to the vault. The second monument, the so-called tower, of large size, has a square plan, surmounted by a circular body. This type of tomb, represented by the tower, is quite widespread in the East and is based on Hellenistic, Asia Minor designs.

The group of small substructures represent the most impressive monument of the site. It is currently in almost the same condition in which it was seen at the end of the 18th Century, except for the central projection and the series of small rooms on the left side, now partly destroyed. It consists of 12 vaulted rooms on two floors. This imposing building, constructed during the late Republican Era, probably contained a public building, perhaps a temple, of which no trace remains.

The thermal baths were built in the 2nd Century A.D. They were restored and expanded in 341 A.D. and restored again in the late 4th or 5th Century A.D. They are situated on an artificial flat area. Only the octagonal room remains visible, since it is partially preserved. 
The theatre is located near the baths. It is constituted of substructures, three to the left, one to the right and is divided horizontally into three parts named (using the Latin terms) summa (higher part), media (average) and ima (lower).

The nymphaeum has two rectangular niches in the apse and two more on the sixth level. An elegant wall with an alternation of niches serves as a facade. The building technique dates the monument between the end of the 1st Century B.C. and the early 1st Century A.D.

The choice of the site has focused on Ocriculum since it represents a quite extended site, characterized by most of the aspects of archaeological places with the advantage that it has been possible to do all the necessary activities for data acquisition and analysis, using flying drones, without interfering with normal visiting activities.

\section{DESCRIPTION OF THE IOE INTEGRATED SYSTEM}

Because of the typical features and restrictions of archaeological sites, characterized by wide open areas, a reduced possibility of installing poles and digging for ground cable ducts and so on, a flexible and modular IoE integrated system $[6,7]$ is needed, which is capable of guaranteeing the desired performances at reasonable cost. It must also be capable of supporting and implementing a proper integrated multidisciplinary model for safety and security management for the specific context, using a multidisciplinary approach [14], paying particular attention also to human factors and the psychological aspects of safety, security, possible emergencies and risk to both control personnel and visitors [15].

The IoE-based integrated safety and security system can use a local control room and mobile terminals available to the safety, security and emergency management personnel and any remote control room positioned at any distance from the site. It can control a number of subsystems and services, to guarantee the achievement of the requested goals, such as

1) properly optimized CCTV;

2) intrusion detection systems correctly positioned;

3) access control;

4) any kind of IoE devices, upcoming installations and monitoring, and so on;

5) wireless networks necessary for personnel devoted to safety and security to manage any kind of critical situation, thanks to the availability of mobile terminals;

6) wireless networks that can be used by visitors, via an app to be installed on their mobile terminals before entering the site, to ensure IoE services such as ordinary and emergency communications; multimedia services to guarantee a better usability of the site such as augmented reality (AR); positioning service aimed at guaranteeing a higher level of safety and security and of management of critical situations; and statistical data about the most visited zones of the site, the time visitors spend at various points in the site, the most popular visiting paths and so on;

7) flying drones controlled by the system for safety, security and emergency administration.

The system warrants a considerable level of modularity which permits adding, at any time, any device, element, system and so on to be integrated in the IoE system.

The architecture of the system is shown in Fig. 2.

The system uses an optical fibre backbone network which passes through the existing cable ducting of the lighting system. In this way, it is possible to minimize the installation costs and it is also possible to guarantee a high-speed network aimed at ensuring high-quality current and future IoE services. If any new lighting system is required, it is possible to use genetic algorithm (GA)-based techniques for the optimization of the wired network necessary for 


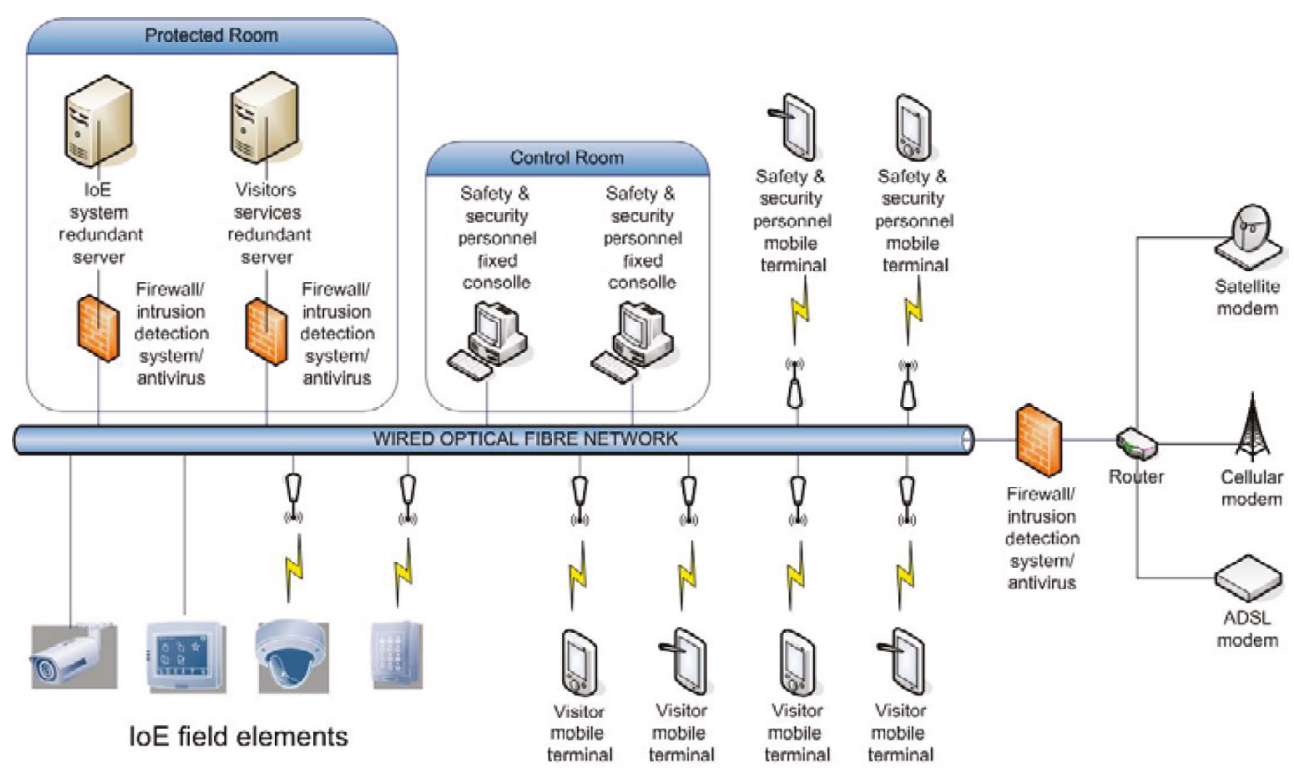

Figure 2: Architecture of the IoE-based integrated system.

installation $[6,7,16]$. It is anyway possible to create a redundant backbone wireless network using the field elements' poles to install wireless bridges.

Both safety and security personnel and visitors use the same wired backbone network, as can be seen from Fig. 2, so it is important to provide the countermeasures necessary to prevent cyberattacks against the integrated system that could originate from the visitors Wi-Fi network [16]. This design choice is due to the limits imposed by the archaeological site which decreases the opportunity for making another wired network dedicated to visitors and which would follow different physical paths, and thus increase the security level of the network and therefore of the whole system [16].

Because of its architecture, which uses wired and wireless networks, the IoE-based system can handle current and future technologies and thus it guarantees considerable modularity and expandability.

The system can connect with all the 'IoE objects', signalling to the operators (personnel in the control room, safety and security personnel, maintenance personnel, police, fire brigades, civil protection and medical staff) for any hazardous or critical situation, in real time, via any means of communication.

A suitable privacy-compliant app, intended for the site, can be installed by safety and security personnel and visitors on their mobile terminals directly when they arrive in the site or in advance. This app permits the use of all the services prearranged for the user (general and AR information, safety and security information, positioning services useful for emergency management, voice over Internet protocol (VoIP) services for ordinary, safety and security and emergency communication with the related personnel and so on) and allows the system to consider the mobile terminals as 'IoE objects' for attaining the exact and desired needs of these archaeological areas. Thanks to this app, it is possible to trace persons by means of both the Global Positioning System (GPS) of the mobile terminals and the Wi-Fi positioning capability of the system (which can operate in underground environments where the GPS signal 
is shielded or weak). In this way, it is possible to obtain useful information for site statistics (followed visiting routes times visitors stay at any point, etc.) and to manage emergencies, if necessary, using the text and VoIP functionalities of the app.

The integrated system is equipped with firewalls, intrusion detection systems and anti-virus software to prevent cyberattack [16]. Since the IoE redundant server provides all the IoE services, it too is properly shielded and protected. For security reasons, the visitor services are hosted by a different redundant server securely connected to the IoE server. The IoE server does not allow visitor access, thus reducing the possibility of cyberattack against it [16].

The system is also equipped with a reliable and resilient remote communication system which can use satellite and cellular networks.

\section{THE METHODOLOGY OF DATA ACQUISITION USING FLYING DRONES}

It is clear from the above that it is necessary to acquire a considerable amount of information on these kinds of sites, to ensure the achievement of the desired goals, taking into consideration all the potential threats and risks (floods, earthquakes, landslides, fires, pollution, industrial accidents, improvised explosive devices, unexploded ordinance, vandalism, theft, terrorism, etc.). This site was chosen because of the large range of threats and risks present (Fig. 3).

First, it was necessary to conduct a detailed analysis of the site and its related monuments, using the relevant historical documentation. All the information derived from this analysis was then used to plan the drone flights.

Before starting the individual flights of the drone, site inspections were made to acquire detailed information aimed at avoiding any kind of problem, including the restrictions related to privacy compliance.

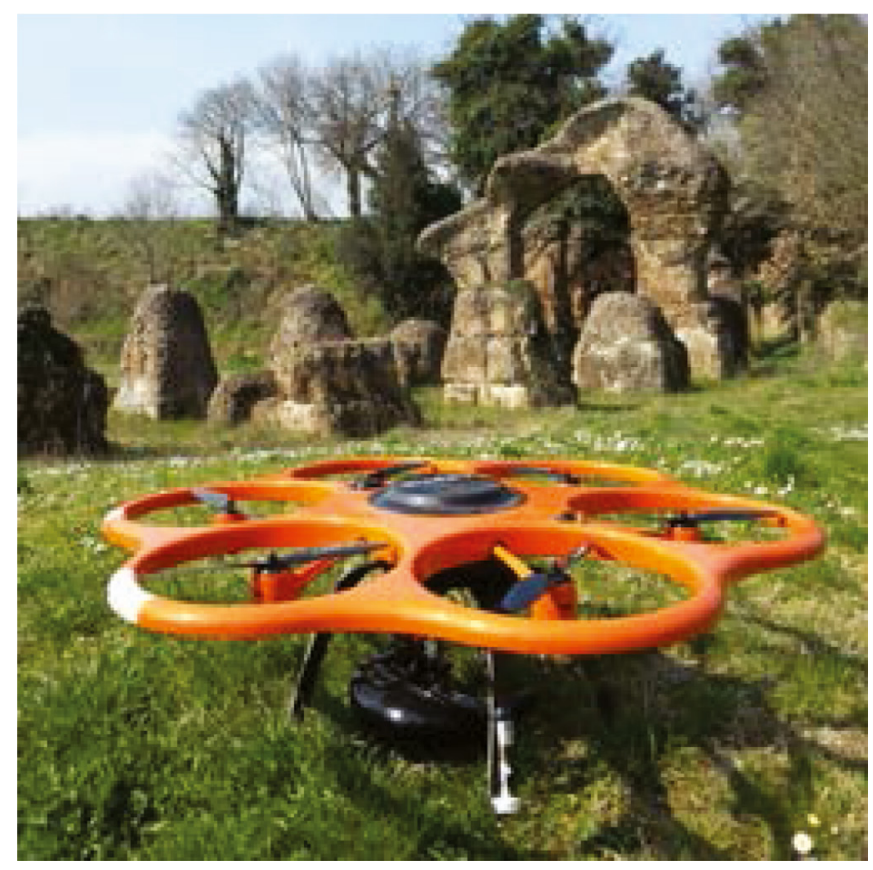

Figure 3: Picture of the flying drone used. In the background is part of the ancient Roman amphitheatre. 
Flight schedules were shared with the archaeological superintendents responsible for the site and the local municipality, taking also into consideration the restrictions existing in Italy for flying drones.

The flights were executed within a period of about 8 months, depending on the restrictions of the site, including also the variability of the weather.

The first flight was aimed at having a general and panoramic view of the site, taking in all the necessary information. The end result was, after post-processing, the ortho-photo that includes the main monuments of the site, as shown in Fig. 4.

A digital elevation map, also known as digital terrain model, was derived from the orthophoto because it was considered useful to have a topographic representation of the site (Fig. 5).

Further individual flights were made over the various monuments of the site. These were aimed at obtaining all the necessary information to derive 3D models of the monuments, necessary for conducting the risk analysis and for designing the IoE integrated system. The flights were made via planned routes that allowed the capture of the different monuments from different points of view, thus also acquiring information related to different shapes and

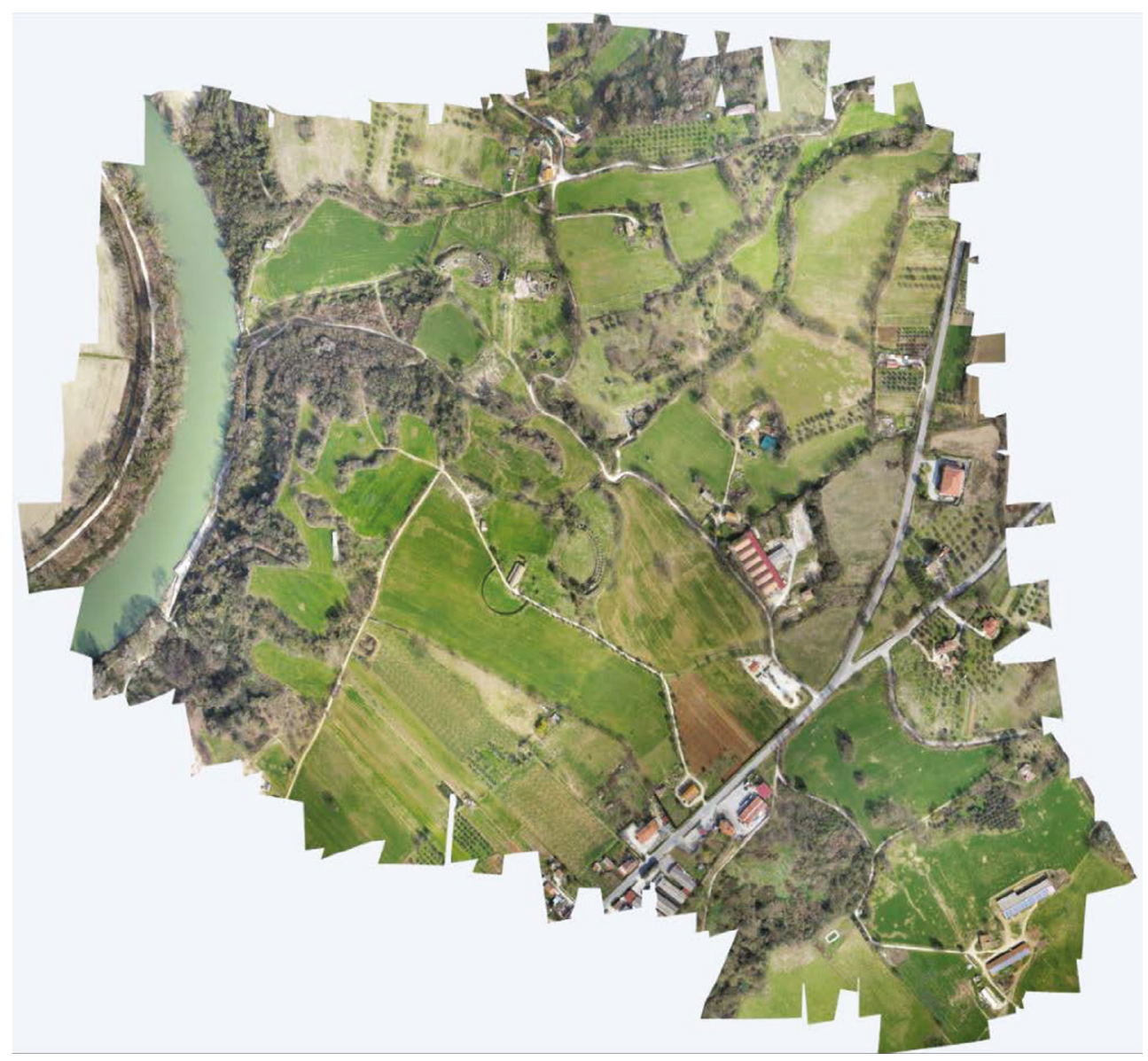

Figure 4: The obtained ortho-photo of the site. 


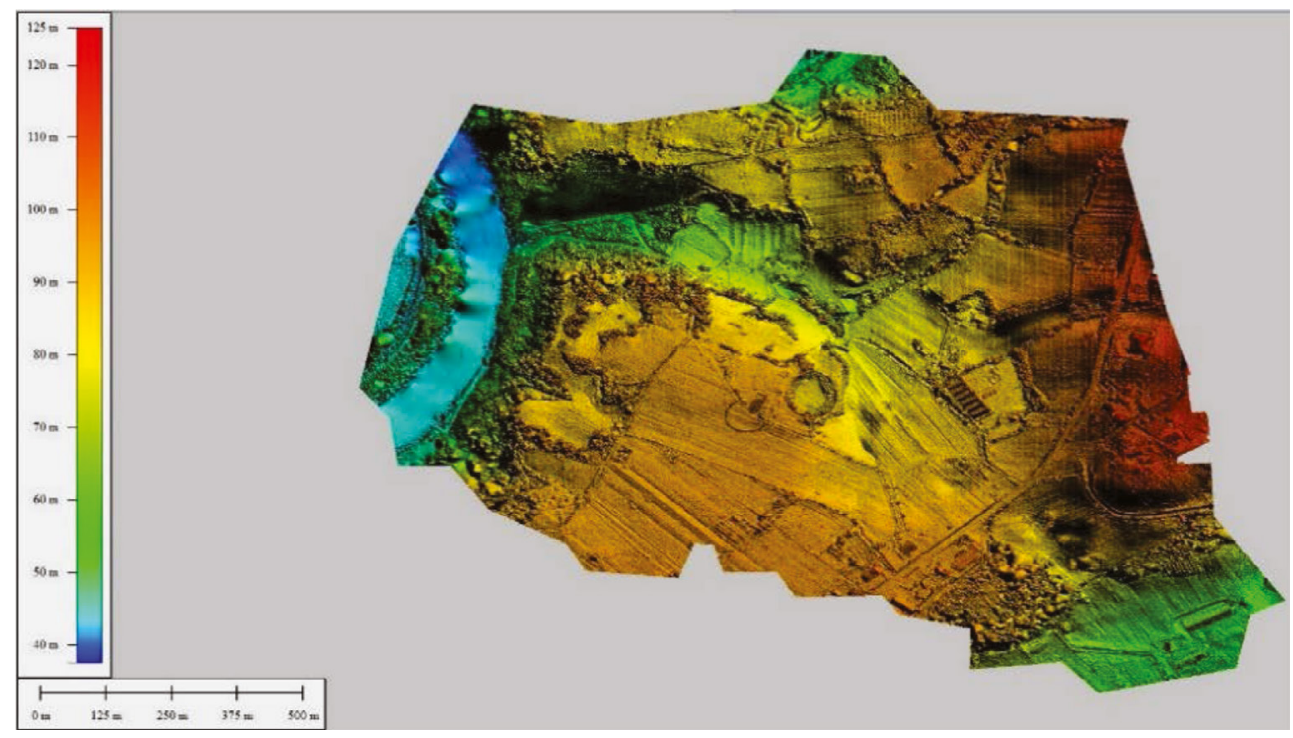

Figure 5: The obtained digital elevation map (DEM) of the site.

objects that define the various monuments. After post-processing, the information derived from the different flights made around each monument was merged to obtain the related 3D models. These models were made on a simple-to-use data format so that they could be viewed using common software and programmes, such as web browsers. In this way, it was possible to exchange information with on-site and remote personnel involved in the work. Further, 3D models permit other useful applications, including restoration, AR studies and so on. An example of 3D model is shown in Fig. 6.

To obtain yet more information, further flights using multi-spectral analysis were made, utilizing a sensor mounted on the drone. An example of a multi-spectral picture is shown in Fig. 7.

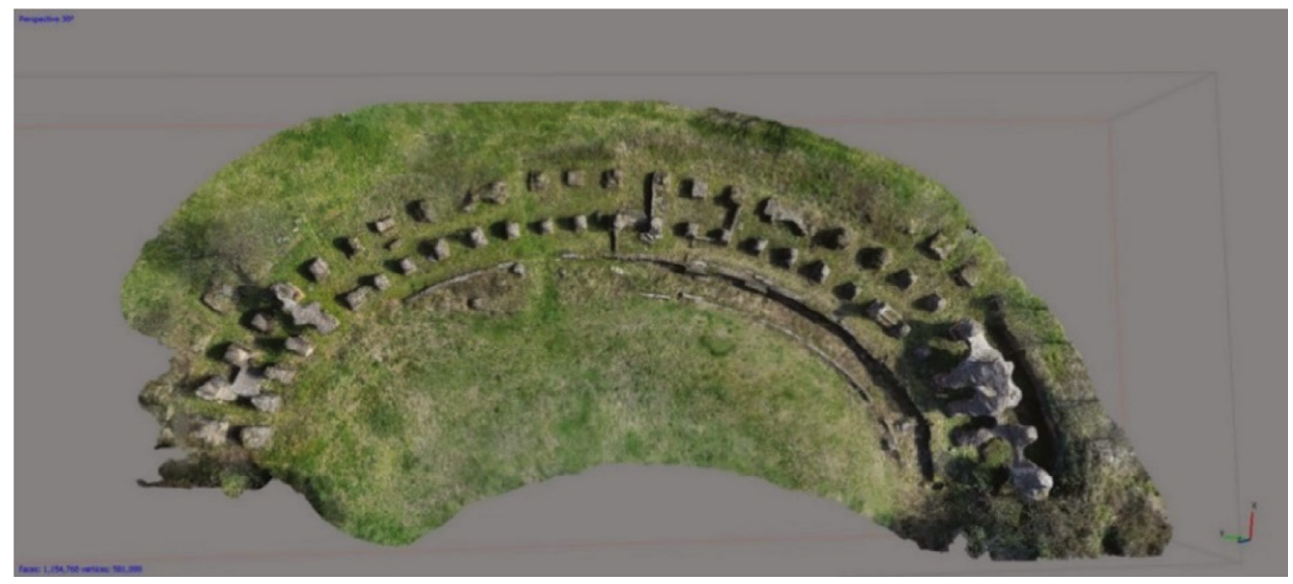

Figure 6: Aerial view of the 3D model of the ancient Roman amphitheatre. 


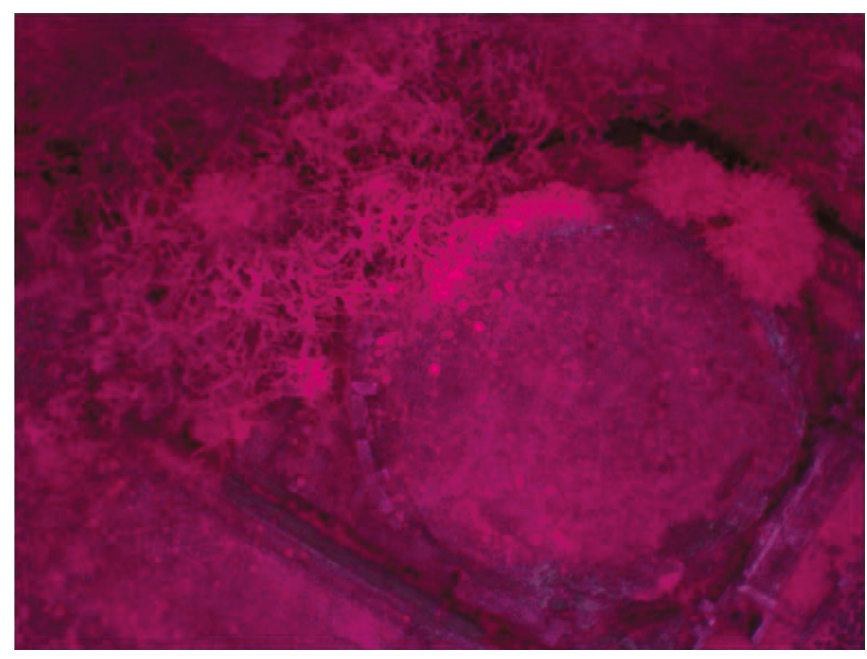

Figure 7: False colour multi-spectral picture of the thermal bath zone of the site.

Further flights were made to obtain the Normalized Difference Vegetation Index (NDVI), map which gives the reflectance difference of the vegetation between the red and the nearinfrared electromagnetic radiation range. This was obtained from a sensor attached to the underside of the drone. The areas with vegetation are characterized by greater values of NDVI while the areas covered by sand, rock and so on are characterized by lower values of NDVI. These kinds of pictures provide very useful information since, if in a typical vegetative area, an unusually high difference of NDVI is present, it could mean there is poor growth of vegetation due to the presence of buried archaeological elements near the surface. This kind of information is useful since, if it is necessary to install a cable duct, these zones should be circumvented to avoid damaging any buried artefacts.

Other valuable data have been attained by mounting a thermal camera on the drone.

An example of a thermal image is shown in Fig. 8.

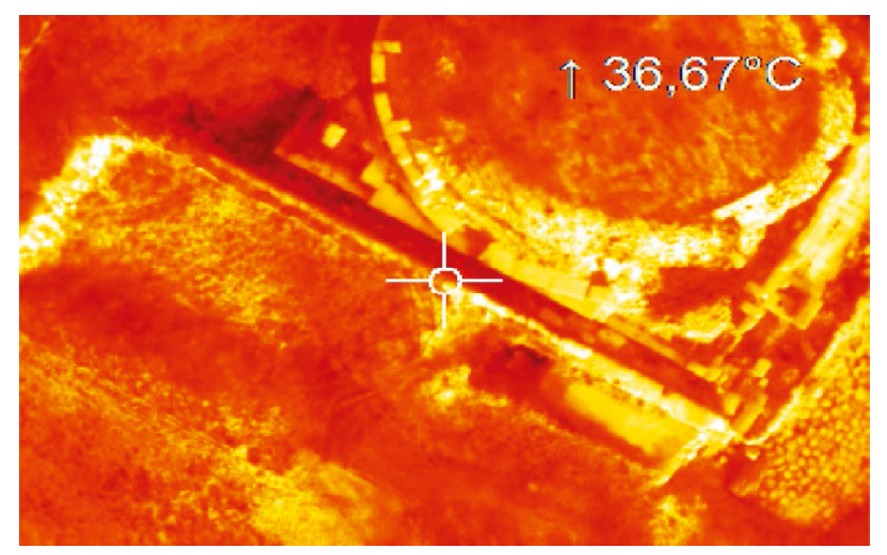

Figure 8: Example of a thermal image taken during one of the drone flights. 
Other important data have been obtained through post-processing of the NDVI images and the thermal images, deriving what are called the ground temperature images which can provide other useful information about visible and buried ruins.

\section{THE RISK ANALYSIS}

Once the above information was obtained, a proper safety and security risk analysis [8-11] was performed to identify all the threats and the risks, to be faced and subsequently reduced by means of the design of an IoE-based integrated system that allows the achievement, finally, of an IoE-SAA. The safety and security risk analysis provides also information about where it is necessary to install field elements, such as Wi-Fi APs and CCTV cameras, to reduce, as much as possible, the risks and the related impacts on safety and security of people and of the cultural heritage of the area. Due to the limited space, it is not possible to illustrate, in detail, the ad hoc risk analysis methodology used for this kind of cultural heritage site.

\section{RESULTS}

To evaluate the performances of the proposed ADAM-FD, different tests of the IoE design system were conducted, using as input the results of data acquisition and of the risk analysis. This evaluation was conducted using the information available as a function of the level of proposed ADAM-FD activities (0\%: no activities, $100 \%$ all the activities).

The design tests of the IoE integrated system were made using advanced techniques such as GA [6], in particular for field elements such as Wi-Fi APs, CCTV cameras, installation poles (to respect the archaeological structures of the site). To ensure minimal final costs, a reduction of final risk level and a high level of reliability and resilience of the system itself, it was necessary to take into consideration the typical structures, restrictions and risks of archaeological areas, as in the one considered.

From this point of view, the significant parameters against which the quality of the results is evaluated are represented by the final IoE system cost and the risk level, as shown in Fig. 9.

As shown in Fig. 9, if no ADAM-FD activity is made (0\%), the cost of the IoE system is maximum (properly normalized at $100 \%$ ), together with the related risk level, since no information is available for an efficient design of the IoE system itself. As the level of ADAM-FD activities increases, more and more details and information about the site are available and the GA can optimize, in the best way, the design of the IoE integrated systems, thus reaching the desired goals.

When all the activities of ADAM-FD are normalized to $100 \%$, GA can ensure a reduction of the IoE integrated system cost, reaching a value of about $26 \%$ with respect to the initial normalized cost and the related risk level, due to the use of the designed IoE system, decreases to about $20 \%$ with respect to the initial normalized risk level.

These results show the good quality performance of the proposed ADAM-FD.

\section{CONCLUSIONS}

A new ADAM-F necessary for the design and implementation of an IoE-based integrated system for the protection of archaeological areas, as well as the people within them, has been presented.

It allows for the acquisition of all the necessary information which, using a multidisciplinary approach, enables the design and the realization of an IoE integrated system capable of ensuring visitor safety and security, cultural heritage preservation and protection as well as good access for visitors, with particular reference to visitors with disabilities. After 


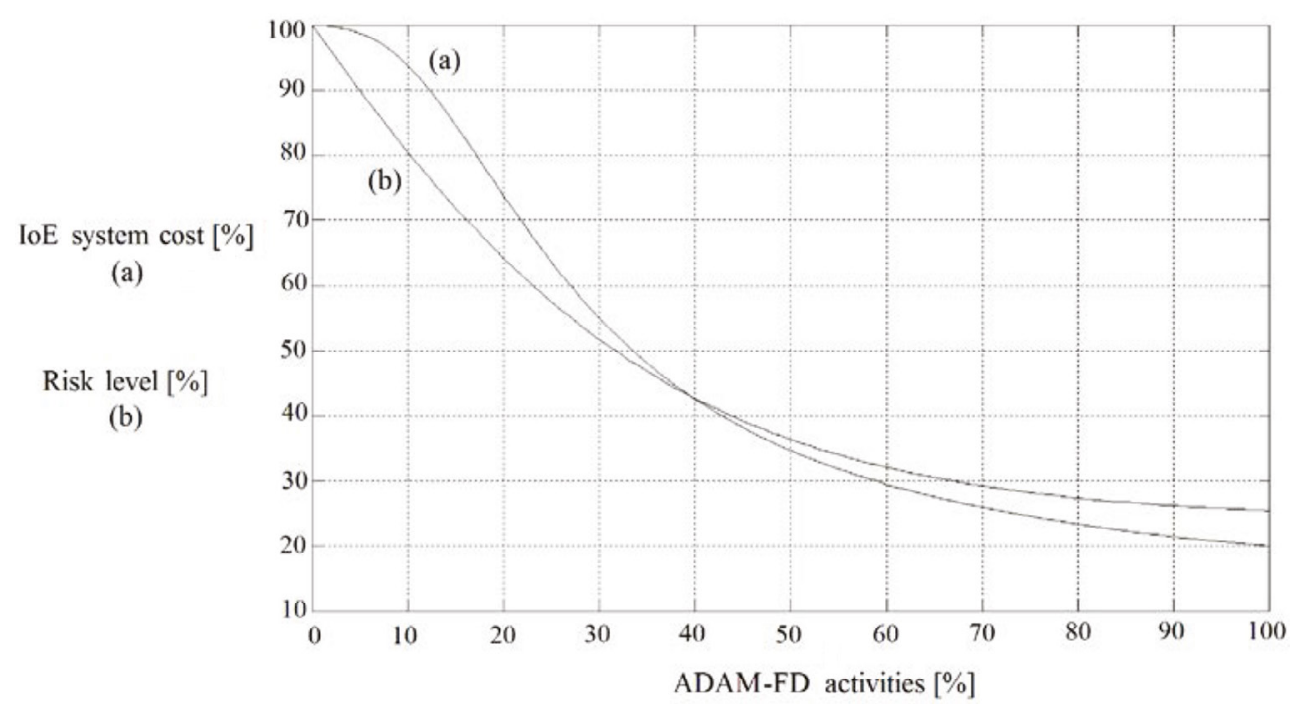

Figure 9: IoE system costs (a) and risk level (b), expressed in percentage, as a function of level of ADAM-FD activities, expressed in percentage.

optimizing the IoE design, the whole system can be built at minimum cost, achieving a reduction of final risk level and a high level of reliability and resilience, considering the typical content and restrictions of archaeological areas.

\section{ACKNOWLEDGEMENTS}

The authors wish to thank the Superintendentr of Archaeological Heritage of Umbria for allowing the development of this experimental study in the archaeological area of Ocriculum and AIVIEWGROUP - European Network of Professionals of the micro-UAV multi-copter and fixed-wing sector, for giving, for free, all the support necessary to conduct the experimental analysis with the drone in the chosen archaeological area.

\section{REFERENCES}

[1] Garzia, F., Sammarco, E. \& Cusani, R., The integrated security system of the Vatican City State,. International Journal of Safety \& Security Engineering, 1(1), pp. 1-17, 2011. DOI: 10.2495/SAFE-V1-N1-1-17.

[2] Contardi, G., Garzia, F. \& Cusani, R., The integrated security system of the Senate of the Italian Republic. International Journal of Safety \& Security Engineering, 1(3), pp. 219 -246, 2011. DOI: 10.2495/SAFE-V1-N3-219-247.

[3] Garzia, F. \& Cusani, R., The integrated safety/security/communication system of the Gran Sasso mountain in Italy. International Journal of Safety \& Security Engineering, 2(1), pp. 13-39, 2012. DOI: 10.2495/SAFE-V2-N1-13-39.

[4] Garzia, F. \& Cusani, R., The safety/security/communication wireless LAN of the underground Gran Sasso mountain national laboratories of the Italian Institute of Nuclear Physics. International Journal of Safety \& Security Engineering, 2(3), pp. 209-226, 2012. DOI: 10.2495/SAFE-V2-N3-209-226. 
[5] Garzia, F., Sammarco, E. \& Cusani, R., Vehicle/people access control system for security management in ports. International Journal of Safety \& Security Engineering, 2(4), pp. 351-367, 2012. DOI: 10.2495/SAFE-V2-N4-351-367.

[6] Garzia, F. \& Papi, L., An Internet of Everything based integrated security system for smart archaeological areas. Proceedings of the Fiftieth Annual IEEE International Carnahan Conference on Security Technology, Orlando, USA, pp. 64-71, 2016.

[7] Garzia, F. \& Sant'Andrea, L., The Internet of Everything Based Integrated Security System of World War I Commemorative Museum of Fogliano Redipuglia in Italy, Proceedings of the Fiftieth Annual IEEE International Carnahan Conference on Security Technology, Orlando, USA, pp. 56-63, 2016.

[8] Lombardi, M., Guarascio, M. \& Rossi, G., The management of uncertainty: model for evaluation of human error probability in railway system. American Journal of Applied Sciences, 11(3), pp. 381-390, 2013. DOI: 10.3844/ajassp.2014.381.390.

[9] Guarascio, M., Lombardi, M., Rossi, G. \& Sciarra, G., Risk analysis and acceptability criteria. WIT Transactions on the Built Environment, 94, pp. 131-138, 2007. DOI: $10.2495 /$ SAFE070131.

[10] Guarascio, M., Lombardi, M. \& Massi, F, Risk Aanalysis in handling and storage of petroleum products. American Journal of Applied Sciences, 10(9), pp. 965-978, 2013. DOI: 10.3844/ajassp.2013.965.978.

[11] Broder, J.F. \& Tucker, E., Risk Analysis and the Security Survey, ButterworthHeineman,: New York, 2012.

[12] Bertacchini, M. \& Cenciaioli, L., Uno sguardo sulla città romana di Ocriculum (Umbria, Italy). II Quaternario - Italian Journal of Quaternary Sciencies, 16(2), pp. 207-216, 2003.

[13] Cenciaioli, L., Ocriculum: guida alla città antica. Archeological Superintendents of Umbria Region (Italy), 2000.

[14] Garzia, F. An integrated multidisciplinary model for security management - optimized implementation technique and related supporting technological system framework. Proceedings of the Fiftieth Annual IEEE International Carnahan Conference on Security Technology, Orlando, USA, pp. 107-114, 2016.

[15] Borghini, F., Garzia, F., Borghini, A. \& Borghini, G., The Psychology of Security, Emergency and Risk, WIT Press, Southampton, 2016.

[16] Garzia, F., Handbook of Communication Security, WIT Press, Southampton, 2013. 